\title{
PENINGKATAN KOMPETENSI GURU MA DARUR RIDHO AL- IRSYAD AL ISLAMIYYAH PADA PEMBELAJARAN DARING MELALUI MOODLE
}

\author{
Sugama Maskar ${ }^{1}$, Putri Sukma Dewi ${ }^{2}$ \\ Universitas Teknokrat Indonesia, ${ }^{\mathbf{1 , 2}}$
}

Email : sugama_maskar@teknokrat.ac.id ${ }^{1}$, putri_sukma@teknokrat.ac.id ${ }^{2}$

\begin{abstract}
Received: (18 November 2020)
Accepted: (1 Maret 2021)

Published : (20 Maret 2021 )

Abstract

Online learning has become something new but a necessity in Indonesia. The use of technology has become more conducive since the issuance of the 2001 National Education Ministerial Decree on distance education. This technological development has resulted in many applications that can support classroom learning, namely moodle and geogebra. The partner in this community service activity is MA Darur Ridho. This school is located in Hanura Village, Teluk Pandan District, Pesawaran Regency. The partner distance from Bandar Lampung is $40 \mathrm{~km}$, so it can be reached in 40 - 60 minutes. MA Darur Ridho has been around for a long time, the average teacher at the school is over 40 years old or senior teachers. This makes it quite difficult for partners to apply online learning. One of the solutions to overcome this problem is by increasing teacher competence in the use of e-learning by holding training for MA Darur Ridho teachers on the use and utilization of elearning as a learning medium. The training venue will be conducted in MA Darur Ridho's computer laboratory and also conducted online through the Zoom Meeting application. Based on the initial and final test scores, before and after the training activities, it shows that MA Darur Ridho teachers have become more understanding and can use the Moodle application mode via the link http://madarurridho.kelasdaring.net/. The results of the data analysis of the scores for the prestest and posttest of the test instruments indicated that the mean scores were 44.9 and 91.3 , respectively. This shows an increase in the initial and final abilities of the training participants. The standard deviation also shows a good spread, namely 8.1 and 3.4.
\end{abstract}

Keywords: Online Learning, Moodle, Training

\begin{abstract}
Abstrak
Pembelajaran dalam jaringan (daring) telah menjadi sesuatu yang baru namun menjadi keharusan di Indonesia. Pemanfaatan teknologi semakin kondusif semenjak dikeluarkannya SK Mendiknas 2001 tentang pendidikan jarak jauh. Perkembangan teknologi ini menghasilkan banyak aplikasi yang bisa mendukung pembelajaran di kelas sebut saja moodle dan geogebra. Mitra dalam kegiatan pengabdian kepada masyarakat ini adalah MA Darur Ridho. Sekolah ini berada di desa Hanura Kecamatan Teluk Pandan Kabupaten Pesawaran. Jarak mitra dari Bandar Lampung adalah $40 \mathrm{~km}$, sehingga dapat ditempuh dengan waktu 40 - 60 menit. MA Darur Ridho telah berdiri cukup lama, rata-rata guru di sekolah tersebut berusia di atas 40 tahun atau guru senior. Hal ini membuat mitra cukup sulit menerapkan pembelajaran dalam jaringan. salah satu solusi untuk mengatasi permasalahan tersebut adalah dengan cara meningkatkan kompetensi guru pada penggunaan e-learning dengan cara mengadakan pelatihan bagi guru-guru MA Darur Ridho mengenai penggunaan dan pemanfaatan elearning sebagai salah satu media pembelajaran. Tempat pelaksanaan pelatihan akan dilakukan di laboratorium komputer MA Darur Ridho dan juga dilaksanakan secara daring melalui aplikasi Zoom Meeting. Berdasarkan nilai tes awal dan tes akhir, sebelum dan sesudah kegiatan pelatihan, menunjukan bahwa guru-guru MA Darur Ridho menjadi lebih memahami dan dapat menggunakan moda aplikasi moodle melalui tautan http://madarurridho.kelasdaring.net. Hasil analisis data dari nilai prestest dan postest instrumen tes menunjukkan bahwa rata-rata nilainya berturut-turut adalah 44,9 dan 91,3. Hal ini menunjukkan adanya peningkatan kemampuan awal dan kemampuan akhir peserta pelatihan. Standar deviasi juga menunjukkan penyebaran yang baik yaitu 8,1 dan 3,4.
\end{abstract}

Kata Kunci: Pembelajaran Daring, Moodle, Pelatihan 
To cite this article:

Maskar, S. \& Dewi, P.S. (2021). Peningkatan Kompetensi Guru MA Darur Ridho Al-Irsyad Al Islamiyyah pada Pembelajaran Daring melalui Moodle. Journal of Technology and Social for Community Service (JTSCS), Vol(2), Page-Page.

\section{PENDAHULUAN}

\section{Analisis Situasi}

Perkembangan teknologi infomrasi berbasis internet atau lebih dikenal sebagai internet of think (IoT) dan robotik dengan balutan revolusi industri 4.0 menjadi salah satu ancaman dan tantangan pada saat bersamaan (Maskar \& Anderha, 2019). Pembelajaran dalam jaringan (daring) telah menjadi sesuatu yang baru namun menjadi keharusan di Indonesia. Sebagaimana menurut Hartanto (2016), dunia pendidikan di Indonesia semakin mengalami perkembangan yang signifikan. Pemanfaatan teknologi semakin kondusif semenjak dikeluarkannya SK Mendiknas 2001 tentang pendidikan jarak jauh. Damayanti, dkk. (2007) juga mengungkapkan bahwa paradigma baru yang muncul terkait dengan proses pembelajaran yang tidak lagi menggambarkan pertemuan tatap muka di dalam kelas meskipun konsep interaksi sosial di dalamnya tetap dipertahankan, kini telah diterima secara luas dan telah begitu mempengaruhi dan berdampak pada kehidupan manusia. Kehadiran teknologi Internet memudahkan orang untuk melakukan interaksi tanpa terikat oleh ruang dan waktu lagi.

Perkembangan teknologi yang sangat pesat juga berpengaruh dalam perkembangan teknologi pendidikan. Sebagaimana yang disampaikan Susiati \& Oktaviana (2018) pada proses pembelajaran saat ini, multimedia mulai banyak digunakan sebagai media pembelajaran untuk membantu guru menyampaikan materi yang ingin disampaikan. Pengunaan media berbasis komputer memberikan pengaruh yang signifikan dalam menumbuhkan daya tarik peserta didik (Mali dalam Saputra \& Febriyanto, 2019). Perkembangan teknologi ini menghasilkan banyak aplikasi yang bisa mendukung pembelajaran di kelas sebut saja moodle dan geogebra. Moodle (Utami, 2016) adalah aplikasi berbentuk web yang memungkinkan siswa masuk dalam kelas digital. Pemerintah juga menggunakan moodle sebagai dasar pengembangan Sistem Pembelajaran dalam Jaringan (SPADA), dan hal tersebut merupakan wujud dari keseriusan pemerintah melalui kemendikbud dalam menjawab tantangan revolusi industri 4.0 (Maskar \& Dewi, 2020). Selain itu, SPADA juga merupakan platform yang dapat menolong guru atau pendidik menghadapi tantangan perkembangan teknologi (Effendi dalam Ulfa \& Puspaningtyas, 2020). Sedangkan GeoGebra (Dikovic, 2009) adalah software geometri dinamis yang membantu membentuk titik, garis, dan semua bentuk lengkungan.

Pembelajaran dalam jaringan memerlukan banyak persiapan dalam pembelajaran. Kemampuan guru dalam mempersiapkan pembelajaran dengan teknologi yang digunakan menjadi sangat perlu. Sedangkan perkembangan yang cepat ini kurang selaras dengan perkembangan kompetensi guru. Menurut Djaja (2017) masih banyak guru yang belum siap menghadapi perubahan teknologi. Guru tidak segera menyesuaikan diri dan belum mampu memotivasi diri untuk terus belajar dengan laju perkembangan dan pengetahuan yang kian berkembang. Sehingga perlu adanya upaya yang dilakukan untuk meningkatkan kompetensi guru. Salah satu caranya dengan peningkatan kompetensi dalam aplikasi moodle dan geogebra. Hal serupa juga terjadi pada MA Darur Ridho.

Berdasarkan hasil wawancara dengan Kepala MA Darur Ridho, sekolah ini sudah melaksanakan pembelajaran daring namun masih memiliki keterbatasan. Keterbatasan tersebut salah satunya adalah media yang digunakan dalam pembelajaran sehingga sulit mengorganisir kegiatan pembelajaran. Dari apa yang dipaparkan Beliau, kami menyadari bahwa baik guru maupun murid masih terbatas pengetahuannya mengenai media yang dapat digunakan dalam pembelajaran berbasis daring. Dari pemaparan di atas maka kami akan melaksanakan pengabdian kepada masyarakat untuk meningkatkan kompetensi guru pada pembelajaran dalam jaringan dengan menggunakan moodle dan geogebra di 
MA Darur Ridho. Kegiatan ini diharapkan dapat membantu proses pembelajaran daring di sekolah tersebut.

\section{Permasalahan Mitra}

Mitra dalam kegiatan pengabdian kepada masyarakat ini adalah MA Darur Ridho. Sekolah ini berada di desa Hanura Kecamatan Teluk Pandan Kabupaten Pesawaran. Jarak mitra dari Bandar Lampung adalah $40 \mathrm{~km}$, sehingga dapat ditempuh dengan waktu 40-60 menit. MA Darur Ridho telah berdiri cukup lama, rata-rata guru di sekolah tersebut berusia di atas 40 tahun atau guru senior. Hal ini membuat mitra cukup sulit menerapkan pembelajaran dalam jaringan.

Pembelajaran dalam jaringan yang sudah terjadi selama ini menggunakan aplikasi WhatsApp. Prosesnya juga cukup rumit karena semua siswa dalam kelas dan semua guru yang mengampu mata pelajaran di kelas tersebut dimasukkan dalam grup. Semua kegiatan pembelajaran dilakukan di dalam grup, absensi, tugas, materi pengumpulan tugas serta ujian. Sehingga cukup sulit mengorganisir kegiatan pembelajaran agar berjalan dengan baik. Kompetensi guru yang masih kurang dalam menguasi teknologi menjadi masalah utama di MA Darur Ridho.

\section{METODE PELAKSANAAN}

\section{Tempat dan Waktu Pelaksanaan}

Tempat pelaksanaan pelatihan dilakukan di laboratorium komputer MA Darur Ridho dan juga dilaksanakan secara daring melalui aplikasi Zoom Meeting. Sedangkan persiapan, penulisan laporan, dan evaluasi dilaksanakan di kampus Universitas Teknokrat Indonesia. Pelaksanaan kegiatan pelatihan dilakukan sebanyak 10 pertemuan, dua pertemuan diluakuan untuk tes kompetensi awal dan akhir dan 8 pertemuan pelaksanan pelatihan dengan durasi 120 menit.

\section{Alat dan Bahan}

Alat dan bahan utama yang dibutuhkan untuk pelaksanaan pelatihan adalah sebagai berikut:

1. Komputer atau laptop.

2. Kuota internet.

3. Domain di kelasdaring.net.

4. Aplikasi Zoom Meeting.

5. Terminal kabel listrik.

\section{Metode Pengumpulan Data}

Untuk mengukur ketercapaian pelatihan pada guru-guru MA Darur Ridho, dilakukan pengumpulan data dengan instrumen tes dan non-tes. Instrumen tes dilakukan dengan dua tahap yaitu tes awal (sebelum pelatihan dimulai) dan tes akhir (setelah pelatihan selesai). Selain itu, untuk mengukur efektifitas output pelaksanaan pelatihan berdasarkan persepsi guru-guru yang mengikuti pelatihan, digunakan instrumen non-tes, yaitu dalam bentuk observasi dan kusioner.

\section{Metode Analisis Data}

Analisis data hasil instrumen tes (tes awal dan tes akhir) dilakukan dengan uji dua rata-rata. Uji dua rata-rata akan menggunakan uji Man Whitney- $U$. Namun, sebelumnya akan dianalisis terlebih dahulu dengan statistik deskriptif. Uji data hasil instrumen non-test (angket) akan dilakukan dengan analisis deskriptif berdasarkan data frekuensi. 


\section{Prosedur Kerja}

Tahapan prosedur kerja pada kegiatan ini dilakukan berdasarkan diagram alir berikut:

(1)

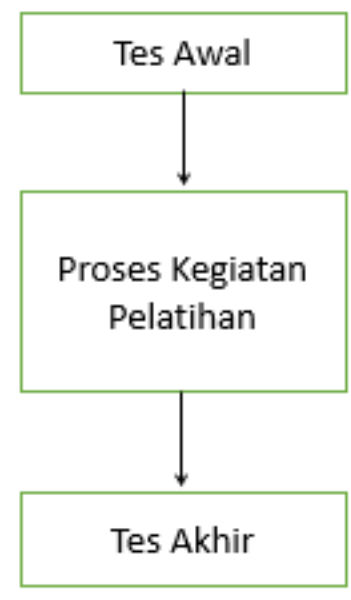

Pengumpulan Data
(2)

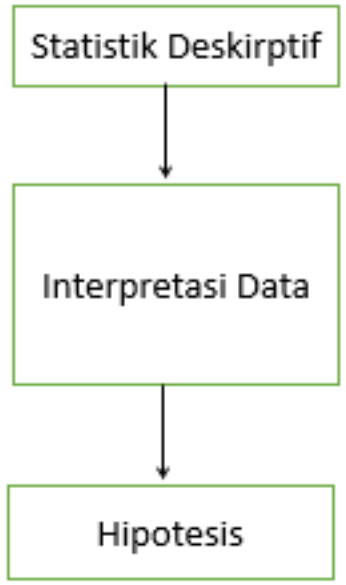

Analisa Hipotesis
(3)

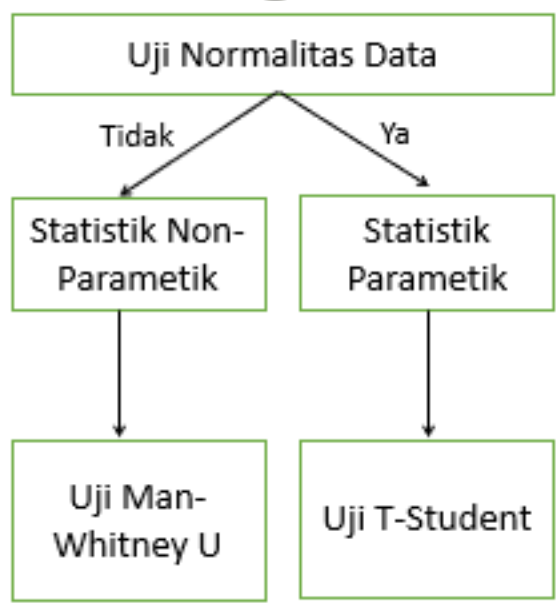

Uji Hipotesis

Gambar 1. Diagram Alir Prosedur Kerja Pelatihan

1. Pengumpulan data: Pada tahap ini, tim melakukan tes kompetensi awal sebagai data awal untuk menguji keberhasilan kegiatan pelatihan yang akan dilaksanakan. Selanjutnya tim melaksanakan pelatihan pada guru-guru di MA Darur Ridho. Pelaksanaan pelatihan dilakukan sebanyak 10 pertemuan degan metode Blended Learning yaitu kombinasi antara tatap muka dan daring. Metode tesebut merupakan metode yang tepat untuk meningkatkan kontrol dalam suatu proses pembelajaran, mengurangi kendala-kendala yang baisa terjadi di dalam kelas, serta dapat mempermudah pengelolaan tugas dan dapat meningkatkan kinerja peserta didik. (Borba dkk dalam Maskar \& Wulantina, 2019). Pada pertemuan terakhir akan tes kompetensi akhir yang datanya akan dibandingkan dengan tes komptensi awal, serta pengisian angket oleh guru-guru yang telah melaksanakan kegiatan pelatihan.

2. Evaluasi dan Pelaporan: Pada tahap ini tim melakukan evaluasi terhadap hasil pelatihan dengan cara mengolah dan menganalisis data tes serta angket. Hasil analisis akan dijadikan acuan keberhasilan pelaksanaan pelatihan tersebut. Selanjutnya, tim akan menulis laporan hasil pelatihan, dari mulai persiapan, pelaksanaan pelatihan sampai hasil evaluasi.

\section{HASIL DAN PEMBAHASAN}

\section{Pengaruh Pelaksanaan Kegiatan}

Berdasarkan nilai tes awal dan tes akhir, sebelum dan sesudah kegiatan pelatihan, menunjukan bahwa guru-guru MA Darur Ridho menjadi lebih memahami dan dapat menggunakan moda aplikasi 
moodle melalui tautan http://madarurridho.kelasdaring.net/. Hasil analisis data dari nilai prestest dan postest instrumen tes menunjukkan bahwa rata-rata nilainya berturut-turut adalah 44,9 dan 91,3. Hal ini menunjukkan adanya peningkatan kemampuan awal dan kemampuan akhir peserta pelatihan. Standar deviasi juga menunjukkan penyebaran yang baik yaitu 8,1 dan 3,4. Hasil analisis deskriptif dari pengujian instrumen tes dapat dilihat pada Tabel 1.

Tabel 1. Hasil analisis deskriptif pretest dan postest

\begin{tabular}{|c|c|c|}
\hline Hasil & Pretest & Post-test \\
\hline Rata-rata & 44,9 & 91,3 \\
\hline Standar deviasi & 8,1 & 3,4 \\
\hline
\end{tabular}

Tabel tersebut menunjukan bahwa terdapat peningkatan yang signifikan pengetahuan dan keterampilkan guru MA Darur Ridho sebelum dan sesudah menggunakan aplikasi moodle. Artinya terdapat peningkatan kompetensi guru dalam menggunakan moodle. Aplikasi moodle sendiri bermanfaat agar proses pembelajaran daring dapat lebih efektif. Hal tersebut dikarenakan aplikasi moodle mempunyai fasilitas yang mendukung keseluruhan standar pembelajaran daring yang ditetapkan oleh pemerintah Indonesia melalui Kemendikbud. Selain itu, moodle juga merupakan salah satu aplikasi yang direkomendasikan dan digunakan kemendikbud untuk pengembangan pembelajaran daring milik pemerintah.

Lebih jauh, Analisis data hasil instrumen tes (tes awal dan tes akhir) dilakukan dengan uji dua rata-rata. Dari hasil uji prasyarat yang dilakukan data tidak berdistribusi normal, karena nilai $X^{2}{ }_{\text {hitung }}>X^{2}{ }_{\text {tabel }}$. Karena data tidak berdistribusi normal maka uji dua rata-rata akan menggunakan uji Man Whitney- $U$. Hasil uji dua rata-rata menunjukkan bahwa $U_{\text {statistika uji }}<U_{\text {tabel }}$, hal ini menunjukkan bahwa ada perbedaan yang signifikan antara hasil pretest dan postest. Dari Tabel 2 dapat kita lihat bahwa rata-rata nilai postest lebih dari nilai pretest. Jadi dapat disimpulkan bahwa kemampuan akhir peserta pelatihan sesudah kegiatan berlangsung lebih dari sebelum kegiatan berlangsung. Hasil uji normalitas dan uji Mann Whitney-U dapat dilihat pada Tabel 2.

Tabel 2. Hasil Uji normalitas data dan Uji Mann Whitney-U

\begin{tabular}{|c|c|c|c|}
\hline Uji chi kuadrat & Nilai & Uji Mann Whitney-U & Nilai \\
\hline$X^{2}{ }_{\text {hitung }}$ & 10,99 & $U_{\text {statistika } u j i}$ & 10,5 \\
\hline$X^{2}{ }_{\text {tabel }}$ & 7,81 & $U_{\text {tabel }}$ & 12 \\
\hline
\end{tabular}

Hasil observasi yang dilakukan selama kegiatan dibagi menjadi tiga proses yaitu pengenalan konsep pembelajaran daring, pelatihan penggunaan aplikasi moodle dan pembuatan tugas untuk setiap materi. Hasil postest peserta pada tiap indikator menunjukkan rata-rata nilai yang baik yaitu 9,1 dari skala 1-10. Hasil tugas peserta juga menunjukkan nilai yang baik pada setiap materi yaitu 90,2. Grafik pencapaian perindikator postest secara rinci dapat dilihat pada Gambar 2 sedangkan hasil analisis tugas peserta pelatihan dapat dilihat dari Gambar 3 . 

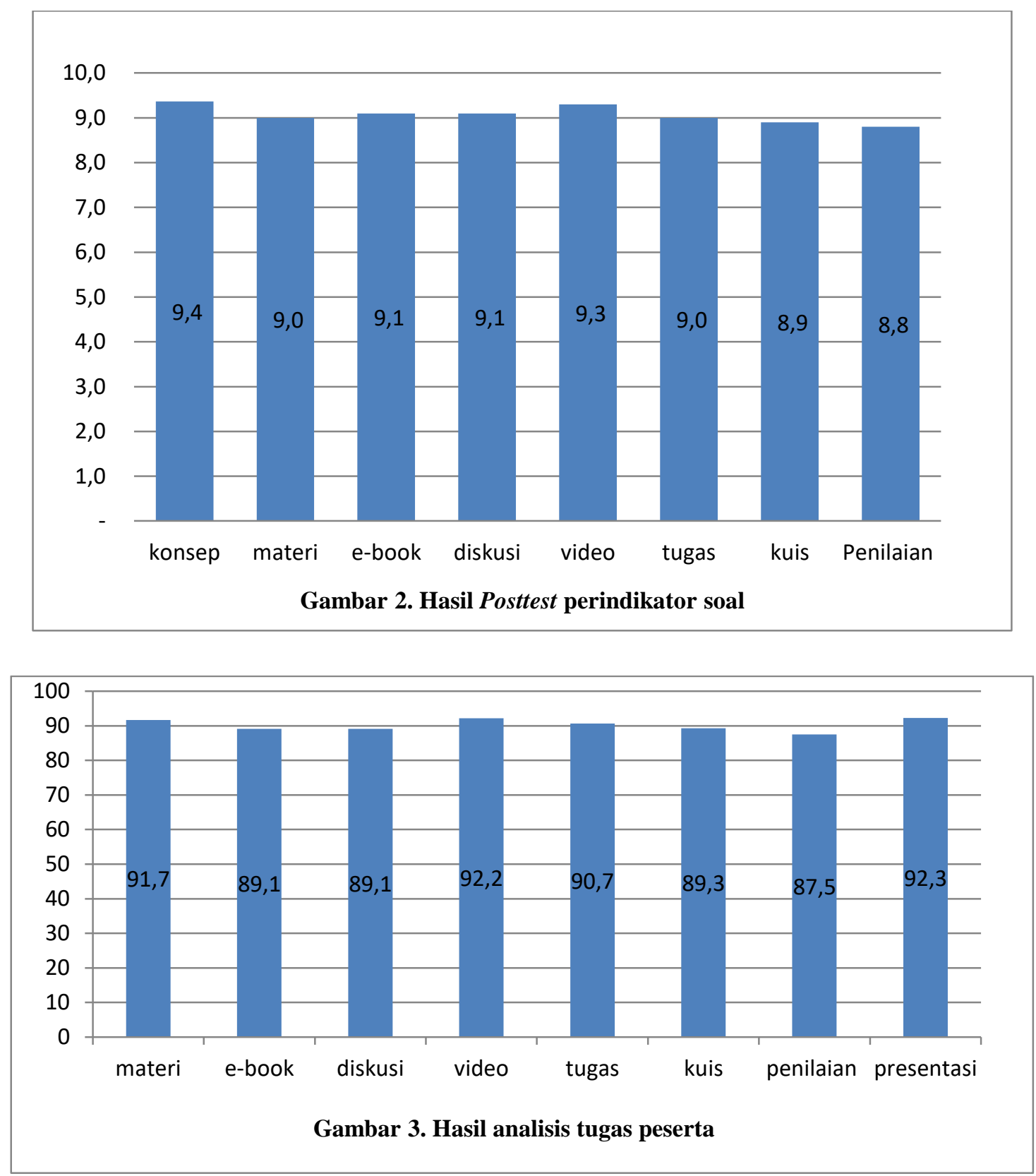

Uji data hasil instrumen non-test (angket) dilakukan dengan analisis deskriptif berdasarkan data frekuensi. Angket efektifitas dilihat dari lima indikator (Bistari:2017) yaitu (1) pengelolaan pelaksanaan pembelajaran, (2) proses komunikatif, (3) respon peserta didik; (4) aktifitas belajar, (5) hasil belajar. Peserta pelatihan memberikan respon yang cukup baik yaitu $80 \%$ peserta sangat setuju pengelolaan pelaksanaan pembelajaran berlangsung dengan baik. Selain itu juga $80 \%$ peserta menjawab sangat setuju tentang hasil belajar yang cukup baik dari pelatihan yang berlangsung. Hal ini menunjukkan bahwa pelatihan yang dilaksanakan telah berlangsung cukup efektif. Hasil analisis angket efektifitas pelatihan dapat dilihat secara rinci pada Tabel 3. 
Tabel 3. Hasil Anslisis Angket Efektifitas Pembelajaran

\begin{tabular}{|l|l|l|l|l|}
\hline \multirow{2}{*}{\multicolumn{1}{c|}{ Indikator }} & \multicolumn{3}{c|}{ Pilihan jawaban } \\
\cline { 2 - 5 } & $\begin{array}{c}\text { Sangat } \\
\text { setuju }\end{array}$ & setuju & $\begin{array}{c}\text { tidak } \\
\text { setuju }\end{array}$ & $\begin{array}{c}\text { sangat } \\
\text { tidak } \\
\text { setuju }\end{array}$ \\
\hline Pengelolaan pelaksanaan pembelajaran & $80 \%$ & $10 \%$ & $10 \%$ & $0 \%$ \\
\hline Proses komunikatif & $60 \%$ & $30 \%$ & $10 \%$ & $0 \%$ \\
\hline Respon peserta didik & $50 \%$ & $40 \%$ & $10 \%$ & $0 \%$ \\
\hline Aktfitas belajar & $70 \%$ & $10 \%$ & $20 \%$ & $0 \%$ \\
\hline Hasil belajar & $80 \%$ & $10 \%$ & $10 \%$ & $0 \%$ \\
\hline
\end{tabular}

Hasil uji dalam bentuk tes dan observasi tersebut menunjukan bahwa pelatihan peningkatakan kompetensi pembelajaran daring guru-guru MA Darur Ridho memberikan pengaruh signifikan pada penggunaan aplikasi moodle.

\section{Kontribusi Mitra Terhadap Pelaksanaan}

Mitra, yaitu MA Darur Ridho Al-Irsyad Al-Islamiyah yang dipimpin oleh Iwan Kurnia, S.Pd.I medukung penuh kegiatan yang dilaksanakan oleh tim dalam rangka meningkatkan komptensi gurugurunya dalam menggunakan aplikasi moodle untuk mengoptimalisasi proses pembelajaran daring di sekolah tersebut. Pak Iwan Kurnia bahkan langsung mengamanatkan pada wakil kepala sekolah dengan surat tugas agar setiap guru dapat mengikuti pelatihan tersebut. Selain itu, komitmen mitra juga terlihat pada kehadiran pada pelatihan. Seluruh perwakilan guru mata pelajaran hadir pada pelatihan tersebut bersama-sama dengan wakil kepala sekolahnya. Seluruh peserta juga antusias dan bersemangat dalam menjalankan pelatihan, walau dengan segala keterbatasan kemampuan literasi teknologi.

Lebih jauh, kontribusi mitra juga diperlihatkan pada dukugan sarana dan prasarana. Mitra menyediakan ruangan dan internet bagi peserta pelatihan. Selain itu mitra juga menyediakan infokus, kipas angin dan sound system agar pelaksanaan pelatihan dapat berjalan lancar. Selain itu, mitra melalui wakil kepala sekolahnya menjadi penjembatan dengan guru-guru untuk dapat berkoordinasi pada pelatihan yang dilakukan secara daring melalui aplikasi Zoom.

\section{KESIMPULAN}

Kegiatan pelatihan peningkatakan kompetensi guru melalui moodle bagi guru MA Darur Ridho, Hanura berjalan dengan baik dan lancar. Kegiatan langsung didukung oleh Kepala Sekolah MA Darur Ridho, Iwan Kurnia, S.Pd.I sebagai mitra dan juga oleh LPPM Universitas Teknokrat Indonesia, sebagai institusi penyelenggara kegiatan PkM.

Kegiatan pelatihan ini memberikan pengaruh yang signifikan terhadap peningkatan kompetensi guru dalam menggunakan aplikasi moodle melalui www.madarurridho.kelasdaring.net Guru MA Darur Ridho yang semula mayoritas menggunakan Whatsapp dalam proses pembelajaran daring pada masa Covid-19 kini bertahap mulai menggunakan moodle sebagai alternatif penggunaan media pembelaran daring. Keunggulan moodle sebagai platform yang memiliki standar sebagai media pembelajaran daring yang diakui oleh pemerintah Republik Indonesia melalui Kemendikbud, membuat pembelajaran daring di MA Darur Ridho dapat lebih efektif. Selain itu, guru-guru juga jadi lebih terampil dalam menggunakan moodle diantaranya; menyusun sistematika materi, membuat tugas, memposting slide, video, dsb.; membuatevaluasi seperti ulangan harian, UTS, dan UAS; mengevaluasi hasil ujian. 
Guru MA Darur Ridho juga memberikan respon positif terhadap penggunaan apikasi moodle yang dikembangkan. Hal tersebut dapat dilihat dari hasil observasi dan angket yang diisi oleh guru MA Darur Ridho mengenai persepsi terhadap platform moodle. Selain itu, hasil koordinasi via Zoom Meeting juga menunjukan bahwa guru-guru MA Darur Ridho sudah mulai terbiasa dan merasa moodle sangat membantu dalam proses pembelajaran daring, terutama pada bagian penugasan dan evaluasi. Selain itu, kemudahan moodle dalam mengintegrasikan platform-nya dengan platform lain dengan teknologi sematkan menjadi keunggulan tersendiri untuk dapat mengefektifkan proses pembelajaran seperti dalam penyematan video melalui YouTube, penyematan tes seara real time, penyematan dengan aplikasi GeoGebra pada pembelajaran matematika dan lainnya.

\section{UCAPAN TERIMA KASIH}

Terima kasih diucapkan penulis pada Universitas Teknokrat Indonesia (UTI) melalui Lembaga Penelitian dan Pengabdian kepada Masyarakat (LPPM) karena berkat hibah internalnya dengan nomor kontrak 18/UTI/LPPM/E.1.2/VII/2020 tanggal 20 Juli 2020, pelaksanaan kegiatan PkM di MA Darur Ridho ini dapat terlaksana dengan baik dan lancar. Selain itu, penulis juga mengucapkan terima kasih kepada mitra PkM, keluarga besar MA Darur Ridho Al-Islamiyah Hanura, Pesawaran. Berkat dukungan darin mitra dan semangat dari guru-guru MA Darur Ridho, kegiatan peningkatakan kompetensi guru pada pembelajaran daring melalui platform moodle ini dapat terlaksana dengan baik dengan menghasilkan luaran sesuai target. Semoga kegiatan ini dapat bermanfaat bagi seluruh pihak yang terlibat, baik secara langsung maupun tidak langsung.

\section{REFERENSI/DAFTAR PUSTAKA}

Darmayanti, T., Setiani, M. Y., \& Oetojo, B. "E-Learning Pada Pendidikan Jarak Jauh: Konsep Yang Mengubah Metode Pembelajaran Di Perguruan Tinggi Di Indonesia," Jurnal Pendidikan Terbuka Dan Jarak Jauh, vol. 8, no. 2, pp. 99-113, 2007.

Susiati, U.D. \& Oktaviana, D. "Desain Aplikasi Media Pembelajaran Untuk Membantu Pemahaman Siswa Tentang Konsep Geometri," Jurnal SAP, vol. 3, no. 1, Agustus 2018.

Utami, Iga S. "Implementasi E-Learning Menggunakan CMS Moodle untuk Meningkatkan Aktivitas Belajar Siswa." Jurnal Komputer Terapan, vol. 2, no. 2, pp. 169-178, 2016.

Diković, L. 2009. "Applications Geogebra into Teaching Some Topics of Mathematics at the College Level," Comsis, vol. 6, no. 2, 2009.

Djaja, Sutrisno. "Harapan dan Tantangan Guru Pembelajar Moda Daring. JURNAL PENDIDIKAN EKONOMI: Jurnal Ilmiah Ilmu Pendidikan, Ilmu Ekonomi dan Ilmu Sosial, vol. 10, no. 2, Januari 2017.

Hartanto, Wiwin. "Penggunaan E-Learning Sebagai Media Pembelajaran," JURNAL PENDIDIKAN EKONOMI: Jurnal Ilmiah Ilmu Pendidikan, Ilmu Ekonomi dan Ilmu Sosial, vol. 10, no. 1, November 2016.

Maskar, S., \& Anderha, R. R. (2019). Pembelajaran transformasi geometri dengan pendekatan motif kain tapis lampung. Mathema Journal, 1(1), 40-47.

Saputra, V. H. \& Febriyanto, E. (2019). Media Pembelajaran Berbasis Multimedia untuk Anak Tuna Grahita. Mathema: Jurnal Pendidikan Matematika, 1(1): 15-23.

Maskar, S., \& Dewi, P.S. (2020). Praktikalitas dan Efektifitas Bahan Ajar Kalkulus Berbasis Daring Berbantuan GeoGebra. Jurnal Cendekia: Jurnal Pendidikan Matematika, 4(2): 888-899.

Ulfa, M., \& Puspaningtyas, N. D. (2020). The Effectiveness of Blended Learning Using A Learning System in Network (SPADA) in Understanding Of Mathematical Concept. Matematika dan Pembelajaran, 8(1), $47-60$.

Maskar, S., \& Wulantina, E. (2019). Persepsi Peserta Didik terhadap Metode Blended Learning dengan Google Classroom. Inovasi Matematika (Inomatika). 1(2), 110-121. 


\section{LAMPIRAN}

Foto Kegiatan
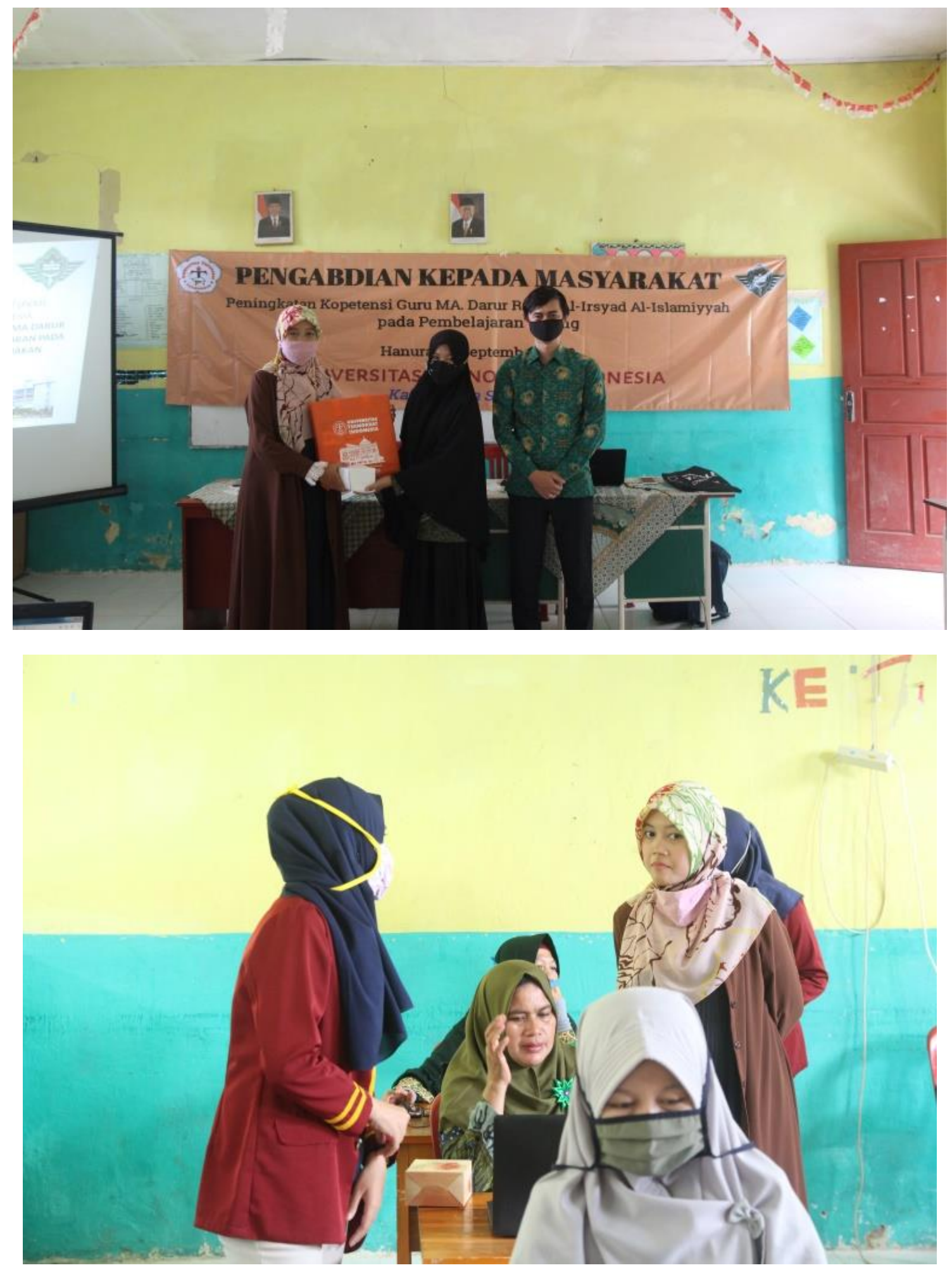


\section{BIOGRAFI PENULIS}

\begin{tabular}{|c|c|}
\hline & $\begin{array}{l}\text { Sugama Maskar, S.Pd., M.PMat. } \\
\text { Sugama Maskar merupakan Dosen di Program Studi S1 Pendidikan } \\
\text { Matematika, Fakultas Sastra dan Ilmu Pendidikan, Universitas Teknokrat } \\
\text { Indonesia. Saat ini juga menjabat sebagai Ketua Program Studi S1 } \\
\text { Pendidikan Matematika di Universitas Teknokrat Indonesia. Sugama aktif } \\
\text { mengajar mata kuliah Kombinatorika, Geometri dan Analisis, serta } \\
\text { Statistika. Bidang keahliannya pada penelitian yaitu pada pengembangan } \\
\text { media dan bahan ajar yang befokus pada pengembangan berfikir } \\
\text { matematis. Selain itu, Sugama juga aktif dalam kegiatan pengabdian pada } \\
\text { masyarakat (PkM) di Provinsi Lampung. Fokus kegiatan PkM Sugama } \\
\text { mayoritas pada pelatihan peningkatakan kompetensi guru padda } \\
\text { penggunaan bahan ajar dan media untuk mengembangkan kemampuan } \\
\text { befikir matematis siswa. }\end{array}$ \\
\hline $\begin{array}{l}\text { i Gur } \\
\text { ada P }\end{array}$ & $\begin{array}{l}\text { Putri Sukma Dewi, S.Pd., M.Pd. } \\
\text { Putri Sukma Dewi merupakan Dosen di Program Studi S1 Pendidikan } \\
\text { Matematika, Fakultas Sastra dan Ilmu Pendidikan, Universitas Teknokrat } \\
\text { Indonesia. Kompetensi keahlian Putri yaitu pada bidang Statistika dan } \\
\text { Matematika Sekolah. Pada bidang penelitian, Putri aktif meneliti pada } \\
\text { pengembangan media pembelajaran berbasis teknologi dengan tujuan } \\
\text { mengembangkan kemampuan befikir matematis peserta didik. Putri juga } \\
\text { memiliki beberapa hak kekayaan intelektual (HKI) atas namanya beserta } \\
\text { tim penelitinya atas pengembangan beberapa media ajar berbasis } \\
\text { teknologi. }\end{array}$ \\
\hline
\end{tabular}

